\title{
MENINGKATKAN KEMAMPUAN BERPIKIR ILMIAH SISWA PAKET B DAN C DI PKBM MENTARI FAJAR MELALUI PELATIHAN SAINS DASAR
}

\author{
I.W. Sumarjaya ${ }^{1}$, M. Joni ${ }^{2}$, N. N. Rupiasih ${ }^{3}$, dan J. Sibarani ${ }^{4}$
}

\begin{abstract}
ABSTRAK
Pendidikan Kesetaraan Belajar Masyarakat atau PKBM merupakan komunitas belajar masyarakat yang melaksanakan pendidikan nonformal untuk siswa yang putus sekolah. Komunitas belajar masyarakat ini dilaksanakan dan dibiayai secara pribadi oleh masyarakat atau yayasan. PKBM Mentari Fajar berlokasi di Kecamatan Kuta Selatan dan saat ini memiliki seratus satu siswa Paket B dan C. Wawancara yang dilakukan terhadap pihak PKBM dan dua puluh siswa Paket B dan C pada akhir bulan Januari 2018 diperoleh kesimpulan perlunya pemahaman cara berpikir ilmiah baik di sekolah maupun di tempat kerja. Kegiatan yang sesuai dengan umpan balik tersebut adalah pelatihan. Tujuan kegiatan pengabdian ini adalah meningkatkan cara berpikir ilmiah siswa paket B dan C melalui pelatihan cara menerapkan sains dasar dalam kehidupan seharihari. Sebelum pelatihan dilaksanakan, kuesioner disebarkan kepada dua puluh siswa dan umpan balik diterima. Pelatihan yang dilaksanakan memperlihatkan antusias siswa dalam memahami dan menerapkan sains dasar dalam kehidupan sehari-hari. Setelah pelatihan dilaksanakan, kuesioner disebarkan untuk memantau dan mendapatkan umpan-balik siswa terhadap kegiatan yang telah dilaksanakan. Umpan balik tersebut menyimpulkan bahwa siswa senang dengan pelatihan dan merasa bahwa kemampuan untuk berpikir ilmiah meningkat secara signifikan.
\end{abstract}

Kata kunci : pendidikan kesetaraan belajar masyarakat, keahlian berpikir ilmiah, pelatihan sains dasar

\begin{abstract}
Pendidikan Kesetaraan Belajar Masyarakat or PKBM is a community learning centre that runs non-formal education for students that dropped out of school. This community learning centre is run and privately funded by a community or a foundation. PKBM Mentari Fajar is located in the Southern Kuta district and currently has one hundred and one students. Interview with PKBM and twenty students conducted in late January 2018 suggest the need of understanding scientific thinking both in school and at work. The aim of this community service is to improve scientific thinking skills to students of Paket B and C by delivering workshop on applying basic science in daily life. Prior to the workshop questionnaires were distributed and feedback were received. The workshop clearly suggests students' enthusiasm in understanding and applying basic science in daily life. After the workshop questionnaires were also distributed to monitor and to obtain students' feedback. Feeback suggest that students' enjoy the workshop and students feel that the ability to think scientifically has improved
\end{abstract}

\footnotetext{
${ }^{1}$ Program Studi Matematika, Fakultas MIPA, Universitas Udayana, sumarjaya@unud.ac.id

${ }^{2}$ Program Studi Biologi, Fakultas MIPA, Universitas Udayana, martinjoni.mj@gmail.com

${ }^{3}$ Program Studi Fisika, Fakultas MIPA, Universitas Udayana, rupiasih@gmail.com

${ }^{4}$ Program Studi Kimia, Fakultas MIPA, Uniiversitas Udayana, sibaranijames@gmail.com
} 
significantly.

Keywords: community learning centre, scientific thinking skill, basic science workshop.

\section{PENDAHULUAN}

Undang-Undang Republik Indonesia Nomor 20 Tahun 2003 tentang Sistem Pendidikan Nasional pasal 26 mengatur secara khusus pendidikan nonformal. Salah satu bentuk pendidikan nonformal yang diselenggarakan oleh masyarakat adalah pusat kegiatan belajar masyarakat (PKBM). PKBM menyelenggarakan pendidikan kesetaraan yang mencakup Program Paket A, Program Paket B, dan Program Paket C. Standar pengelola PKBM diatur dalam Peraturan Menteri Pendidikan Nasional Republik Indonesia Nomor 44 Tahun 2009 tentang Standar Pengelola Pendidikan pada Program Paket A, Paket B, dan Paket C.

Keberadaan PKBM telah membantu siswa yang putus sekolah atau belum sempat menyelesaikan pendidikan formal. Terdapat lima faktor yang menyebabkan seseorang terhambat dalam menyelesaikan pendidikan formal yaitu ekonomi, waktu, geografi, keyakinan dan sosial/hukum (Yuaelawati et al., 2008). Lihat juga factor-faktor lain penyebab putus sekolah ini pada Sumarjaya dkk. (2016) dan Sumarjaya dkk. (2017).

PKBM Mentari Fajar merupakan salah satu PKBM yang beralamat di Jalan Goa Gong, Gang Mentari, Banjar Angga Swara, Lingkungan Batu Ngongkong, Desa Jimbaran. PKBM ini didirikan pada tahun 2010 dengan izin operasional nomor 1151 tahun 2010 dan menyelenggarakan pendidikan kesetaraan Paket A, Paket B, dan Paket C. Khusus untuk program Paket C, PKBM ini memiliki program kesetaraan untuk ilmu pengetahuan sosial (IPS).

Studi awal berupa wawancara dengan pengelola PKBM dan pemberian kuesioner kepada dua puluh siswa Paket B dan C pada akhir Januari tahun 2018 mendapatkan hasil bahwa siswa-siswa tersebut mengalami kesulitan dalam berpikir secara ilmiah yang dapat dilihat dalam penerapan sains dasar dalam pembelajaran. Menteri Pendidikan dan Kebudayaan dalam Reza (2017) mengatakan bahwa seiring dengan kebutuhan sumber daya manusia yang meningkat, pendidikan nonformal seperti kursus dan pelatihan memegang peranan yang sangat penting. Dengan kata lain kemampuan berpikir ilmiah (scientific thinking) memegang peranan penting. Sains dasar yang dimaksud dalam kegiatan ini adalah biologi, fisika, dan kimia. Selain masalah tersebut di atas, para siswa Paket B dan C juga mengalami kesulitan dalam menerapkan konsep sains ini dalam sehari-hari.

Permasalahan sulitnya memahami dan menerapkan sains dasar yang didapat oleh para siswa Paket B dan C tersebut dapat disebabkan oleh hal-hal berikut. Pertama, materi yang cukup susah dan padat sehingga memerlukan waktu baik untuk latihan maupun belajar. Selain itu, kurangnya prasarana untuk mempraktikkan sains dasar dalam suatu laboratorium atau bengkel menyebabkan siswa sulit membayangkan bagaimana konsep sains dasar baik dalam pelajaran maupun dalam kehidupan sehari-hari. Di lain pihak, para siswa tersebut sebagian besar sudah bekerja sehingga kesulitan dalam mengatur waktu untuk belajar.

Berdasarkan hasil wawancara dan pengamatan yang telah dilakukan di PKBM Mentari Fajar diputuskan bahwa para siswa Paket B dan Paket C memerlukan bagaimana teknik dan strategi dalam mempelajari sains dasar dan menerapkannya dalam kehidupan sehari-hari baik selama belajar di PKBM maupun saat bekerja.

Artikel ini disusun sebagai berikut. Bagian pertama membahas latar belakang pentingnya cara berpikir ilmiah bagi siswa Paket B dan C di PKBM Mentari Fajar dan bentuk kegiatan pengabdian 
yang sesuai untuk menyelesaikan permasalahan ini. Selanjutnya, bagian kedua membahas metode pelaksanaan kegiatan pengabdian mulai dari perancangan prauji, pelaksanaan pelatihan, dan pascauji. Bagian ketiga memuat hasil dan pembahasan dari pelatihan yang telah dilaksanakan serta umpan balik siswa Paket B dan C. Bagian keempat memuat kesimpulan dan saran untuk kegiatan pengabdian yang telah dilakukan.

\section{METODE PELAKSANAAN}

Berdasarkan tujuan, manfaat, dan pemecahan masalah seperti yang diuraikan pada bagian pendahuluan serta melihat khalayak sasaran strategis untuk kegiatan pengabdian ini maka yang cocok untuk kegiatan ini adalah pelatihan (workshop) berupa presentasi, demonstrasi berpikir ilmiah, dan interaksi langsung dengan para siswa paket B dan C dalam mempraktikkan sains sederhana.

Materi pelatihan berpikir ilmiah terdiri atas empat bagian penting. Bagian pertama berupa pengenalan cara berpikir ilmiah. Materi pada bagian ini meliputi mengenalkan cara berpikir induksi, deduksi, causal reasoning, formasi konsep, dan uji hipotesis (lihat Dunbar dan Klahr, 2012). Bagian kedua adalah praktik sains sederhana. Materi pada bagian kedua ini meliputi contoh praktis dan praktik sains sederhana seperti pengenalan kimia dalam kehidupan sehari-hari. Aplikasi sains merupakan bagian penting ketiga dalam pelatihan ini. Bagian ini meliputi aplikasi cara berpikir ilmiah misalnya bagaimana proses fotosintesis dan peranan tanaman baik dari segi fungsi maupun estetika. Bagian terakhir adalah pengayaan materi. Pengayaan ini meliputi diskusi materi yang sudah diajarkan dan mengaitkannya dengan pembelajaran di kelas dan tempat kerja.

\section{HASIL DAN PEMBAHASAN}

Prauji berupa kuesioner yang diberikan kepada dua puluh siswa PKBM yang terdiri dari tujuh siswa Paket B dan tiga belas siswa Paket C. Sebelas orang dari dua puluh siswa tidak melanjutkan pengisian kuesioner karena menjawab "Tidak" pada butir pertama pada kuesioner. Secara garis besar kuesioner dibagi menjadi pertanyaan tertutup (dengan menjawab "Ya" atau "Tidak") dan pertanyaan terbuka yang mengharuskan siswa memberikan masukan (ditandai tanda*)

Tabel 3.1 Hasil kuesioner prauji.

\begin{tabular}{|l|l|l|l|}
\hline \multirow{2}{*}{ No. } & Pertanyaan & \multicolumn{2}{l|}{ Jawaban } \\
\cline { 3 - 4 } & & Ya & Tidak \\
\hline 1. & $\begin{array}{l}\text { Apakah Anda pernah bertanya tentang fenomena-fenomena yang terjadi di } \\
\text { alam sekitar dalam kehidupan sehari-hari? }\end{array}$ & 9 & 11 \\
\hline 2. & Apakah Anda ingin tahu kenapa fenomena tersebut terjadi? & 8 & 1 \\
\hline 3. & $\begin{array}{l}\text { Berkaitan dengan pertanyaan nomor 2, apakah Anda pernah mencari tahu } \\
\text { informasi tersebut melalui buku, majalah, atau Internet? (misalnya melalui } \\
\text { smartphone) }\end{array}$ & 8 & 1 \\
\hline 4. & $\begin{array}{l}\text { Apakah dalam pekerjaan sehari-hari Anda pernah disuruh melakukan } \\
\text { pekerjaan yang menuntut cara berpikir ilmiah seperti pada pertanyaan 3? }\end{array}$ & 8 & 1 \\
\hline 5. & $\begin{array}{l}\text { Apakah menurut Anda keahlian berpikir ilmiah seperti pada pertanyaan } 4 \\
\text { diperlukan dalam pekerjaan? }\end{array}$ & 8 & 1 \\
\hline 6. & Apakah Anda pernah mendengar kata sains? & 8 & \\
\hline 7. & $\begin{array}{l}\text { Seberapa penting sains menurut Anda dalam kehidupan sehari-hari?* } \\
\text { Tujuh } \\
\text { menjawab } \\
\text { penting, } \\
\text { orang menjawab } \\
\text { tidak penting }\end{array}$ \\
\hline
\end{tabular}




\begin{tabular}{|c|c|c|}
\hline 8. & $\begin{array}{l}\text { Pernahkah Anda melakukan sains sederhana dalam kehidupan sehari-hari. } \\
\text { Sebagai contoh membengkokkan air menggunakan sisir atau membuat } \\
\text { roket balon misalnya?* }\end{array}$ & $\begin{array}{lr}\text { Empat } & \text { orang } \\
\text { menjawab } & \\
\text { pernah } & \text { dan } \\
\text { empat } & \text { orang } \\
\text { menjawab } & \text { tidak } \\
\text { pernah } & \\
\end{array}$ \\
\hline 9. & $\begin{array}{l}\text { Apakah Anda pernah disuruh membuat sejenis laporan dalam pekerjaan } \\
\text { yang menuntut keahlian berpikir secara ilmiah dalam pekerjaan? }\end{array}$ & \begin{tabular}{l|l}
1 & 7 \\
\end{tabular} \\
\hline 10. & $\begin{array}{l}\text { Menurut Anda apa manfaat yang diperoleh jika kita tahu cara berpikir } \\
\text { ilmiah dalam kehidupan sehari-hari?* }\end{array}$ & \\
\hline
\end{tabular}

Oleh karena hanya sembilan orang yang mengisi kuesioner secara lengkap, melakukan uji validitas dan reliabilitas tidak bisa dilakukan. Dalam hal ini, analisis hanya dilakukan secara deskriptif. Berdasarkan Tabel 4 para siswa menganggap cara berpikir ilmiah merupakan bagian penting dalam kehidupan sehari-hari, meskipun secara eksplisit para siswa tersebut belum pernah membuat laporan yang menuntut kemampuan berpikir ilmiah.

Berdasarkan hasil kuesioner pada Tabel 3.1 dan koordinasi tim pengabdi dengan pihak PKBM diputuskan bahwa kegiatan sesuai untuk kegiatan Program Udayana Mengabdi ini adalah pelatihan (workshop) sehari. Workshop ini telah dilaksanakan pada tanggal 22 September 2018 dan diikuti oleh sebelas orang (delapan orang dari sebelas orang berpartisipasi pada pengisian prauji). Materi pelatihan diawali dengan presentasi cara berpikir ilmiah dan penayangan beberapa video tentang contoh-contoh nyata berpikir ilmiah dalam kehidupan sehari-hari. Video aplikasi cara berpikir ilmiah diambil dari YouTube. Kemudian dilanjutkan dengan pemberian materi berupa kimia dalam kehidupan sehari-hari, seperti ditunjukkan oleh Gambar 3.1

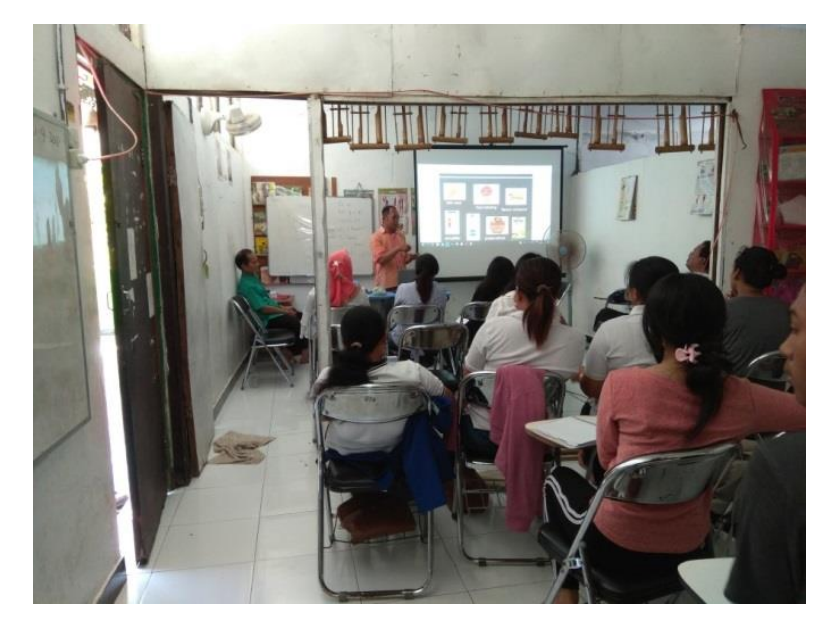

Gambar 3.1 Pemberian materi workshop tentang kimia dalam kehidupan sehari-hari.

Materi ketiga adalah materi tentang peranan tumbuh-tumbuhan dalam kehidupan sehari-hari dan bagaimana memanfaatkan tumbuhan sebagai sumber oksigen dan sebagai penambah estetika di dalam ruangan. 


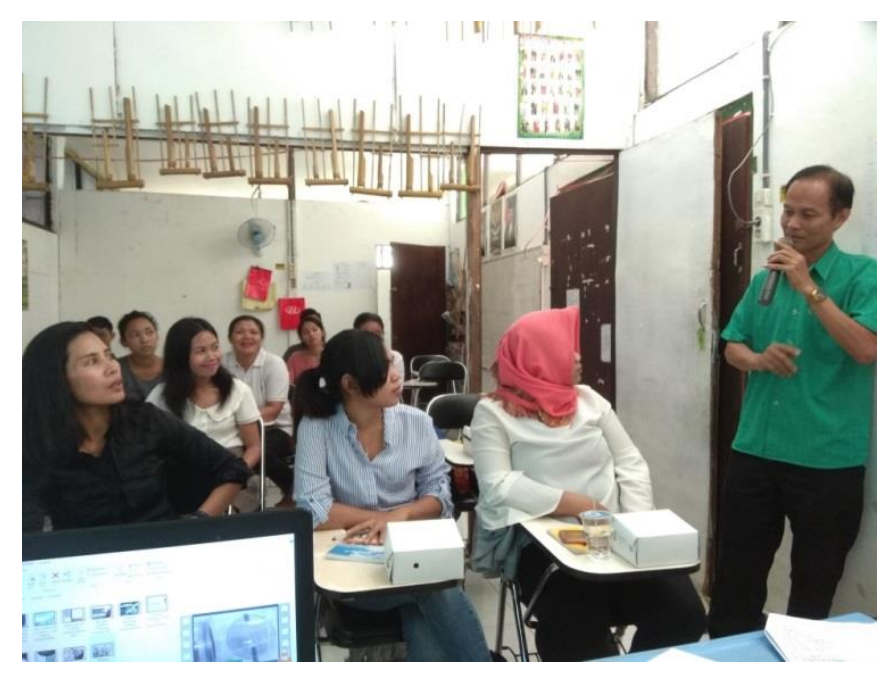

Gambar 3.2 Pemberian materi workshop tentang biologi tumbuhan dalam kehidupan sehari-hari.

Selama pelatihan berlangsung peserta antusias dalam bertanya mengenai kimia dalam kehidupan sehari-hari dan dampak negatif bahan-bahan kimia obat bagi kesehatan dalam jangka panjang. Selain itu, antusiasme siswa juga terlihat dalam sesi tentang biologi tumbuhan dalam kehidupan sehari-hari. Utamanya adalah tanaman apa yang bisa digunakan secara praktis baik bagi kesehatan dan dari segi estetika sesuai untuk ditempatkan di dalam rumah.

Seminggu setelah pelatihan, kuesioner pascauji pun diberikan. Kuesioner berisi delapan pertanyaan: tujuh mengonfirmasi pertanyaan dengan menjawab "Ya" dan "Tidak"; satu pertanyaan berupa pertanyaan terbuka yang meminta saran peserta pelatihan. Semua peserta pelatihan berpartisipasi dalam pengisian kuesioner tersebut dan hampir semua menjawab senang mengikuti workshop dan ingin workshop sejenis dilaksanakan lagi, kecuali satu jawaban yang tidak valid.

Tabel 3.2 Hasil kuesioner pascauji

\begin{tabular}{|c|c|c|c|}
\hline \multirow[t]{2}{*}{ No. } & \multirow[t]{2}{*}{ Pertanyaan } & \multicolumn{2}{|c|}{ Jawaban } \\
\hline & & $\mathrm{Ya}$ & Tidak \\
\hline 1. & $\begin{array}{l}\text { Apakah menurut Anda workshop yang telah dilaksanakan pada hari Sabtu, } \\
22 \text { September } 2018 \text { tersebut menarik? }\end{array}$ & 10 & 1 \\
\hline 2. & $\begin{array}{l}\text { Apakah menurut Anda workshop tersebut membantu Anda dalam } \\
\text { memahami cara berpikir ilmiah? }\end{array}$ & 9 & 1 \\
\hline 3. & $\begin{array}{l}\text { Apakah Anda mendapatkan informasi atau pengetahuan yang baru setelah } \\
\text { mengikuti workshop? }\end{array}$ & 10 & \\
\hline 4. & $\begin{array}{l}\text { Materi pertama dalam workshop adalah pengenalan cara berpikir ilmiah } \\
\text { secara konsep melalui penayangan beberapa video. Menurut Anda apakah } \\
\text { materi tersebut membantu dalam membuka wawasan dalam berpikir } \\
\text { ilmiah? }\end{array}$ & 10 & \\
\hline 5. & $\begin{array}{l}\text { Materi kedua dalam workshop adalah pengenalan dan aplikasi kimia dalam } \\
\text { kehidupan sehari-hari. Menurut Anda apakah materi tersebut membantu } \\
\text { membuka wawasan dalam berpikir ilmiah? }\end{array}$ & 10 & \\
\hline 6. & $\begin{array}{l}\text { Materi ketiga dalam workshop adalah pengenalan biologi berupa tanaman } \\
\text { dan fungsinya dalam kehidupan sehari-hari. Menurut Anda apakah materi } \\
\text { tersebut membantu membuka wawasan dalam berpikir ilmiah? }\end{array}$ & 9 & 1 \\
\hline 7. & $\begin{array}{l}\text { Apakah workshop yang telah dilakukan dapat meningkatkan cara berpikir } \\
\text { ilmiah Anda? }\end{array}$ & 10 & \\
\hline 8. & $\begin{array}{l}\text { Menurut Anda apa bisa dilakukan untuk memperbaiki workshop ini ke } \\
\text { depannya? }\end{array}$ & & \\
\hline
\end{tabular}


Pada butir pertanyaan kedelapan berupa saran untuk memperbaiki workshop beberapa siswa minta agar pelatihan serupa dilaksanakan lagi dan waktu pelaksanaan diperpanjang. Selain itu saran juga diberikan kepada para narasumber agar narasumber dalam menyajikan materi lebih memperhatikan peserta sehingga materi lebih jelas dan mudah disimak. Umpan balik pascauji ini dapat dilihat dalam Sumarjaya dkk. (2018).

\section{KESIMPULAN DAN SARAN}

Pelatihan (workshop) yang sudah dilakukan telah mampu memberikan gambaran tentang cara berpikir ilmiah kepada siswa Paket B dan C. Antusiasme para siswa terlihat mulai dari pemberian prauji, pelatihan, dan pemberian pascauji yang sekaligus juga berperan sebagai alat memantau dan mengevaluasi kegiatan.

\section{UCAPAN TERIMA KASIH}

Ucapan terima kasih disampaikan kepada Rektor Universitas Udayana melalui Ketua Lembaga Penelitian dan Pengabdian kepada Masyarakat Universitas Udayana atas pendanaan kegiatan pengabdian ini yang bersumber dari DIPA PNBP Universitas Udayana Tahun Anggaran 2018 sesuai dengan Surat Perjanjian Penugasan Pelaksanaan Hibah Pengabdian kepada Masyarakat Udayana Mengabdi dan Hibah Udayana untuk Masyarakat dana PNBP Nomor: 384-64/UN14.4.A/PM/2018, tanggal 29 Maret 2018. Terima kasih juga disampaikan kepada pihak PKBM Mentari Fajar dan para siswa paket B dan C yang telah berpartisipasi dalam seluruh rangkaian kegiatan pengabdian ini.

\section{DAFTAR PUSTAKA}

Dunbar, K. N. and Klahr, D. (2012). Scientific Thinking and Reasoning. In: Holyoak, K. J. and Morrison, R. G. (eds.) The Oxford Handbook of Thinking and Reasoning. New York: Oxford University Press.

Reza (2017). Mendikbud: Pendidikan Nonformal Punya Peranan Penting [Online]. Available: http://news.liputan6.com/read/3093586/mendikbud-pendidikan-nonformal-punya-peranan-penting [Diakses tanggal 18 February 2018].

Sumarjaya, I. W., Joni, M., Rupiasih, N. N. and Sibarani, J. (2016). Laporan Akhir Hibah Udayana Mengabdi: Meningkatkan Kompetensi Siswa Paket B dan C di PKBM Mentari Fajar Melalui Pelatihan Perangkat Lunak Perkantoran. Universitas Udayana.

Sumarjaya, I. W., Joni, M., Rupiasih, N. N. and Sibarani, J. (2017). Laporan Akhir Hibah Udayana Mengabdi: Meningkatkan Kemampuan Pemecahan Masalah Matematika Siswa Paket B dan C di PKBM Mentari Fajar. Universitas Udayana.

Sumarjaya, I. W., Joni, M., Rupiasih, N. N., dan Sibarani, J. (2018). Meningkatkan Kemampuan Berpikir Ilmiah Siswa Paket B dan C di PKBM Mentari Fajar Melalui Pelatihan Sains Dasar, Laporan Akhir Hibah Udayana Mengabdi (Tidak diterbitkan), Kampus Bukit Jimbaran, Universitas Udayana.

Yuaelawati, E., Syihab, U., Kamil, M., Priatna, N. and Nugroho, S. P. (2008). Acuan Proses Pelaksanaan dan Pembelajaran Pendidikan Kesetaraan Program Paket A, Paket B, dan Paket C, Direktorat Pendidikan Kesetaraan, Direktorat Jenderal Pendidikan Non Formal dan Informal, Departemen Pendidikan Nasional, Jakarta. 